\title{
NOMES DE BAIRROS DE SÃO LUÍS DO MARANHÃO: o que revelam os topônimos oriundos de algumas siglas institucionais?
}

\author{
NAMES OF NEIGHBORHOODS IN SÃO LUÍS OF MARANHÃO: what do the \\ toponyms from some institutional acronyms reveal?
}

Gabriel Pereira CASTRO*

Universidade Federal do Maranhão (UFMA)

Heloísa Reis CURVELO-MATOS ${ }^{* *}$

Universidade Federal do Maranhão (UFMA)

RESUMO: O presente artigo investiga os nomes de bairros da Capital do Maranhão, São Luís, especificamente, aqueles surgidos a partir de siglas institucionais, isto é, siglas de institutos e/ou cooperativas que financiavam moradias para a sociedade civil ou a seus associados. Convém aclararmos que esse é um traço bastante característico do processo habitacional de São Luís, justificando assim nosso estudo. Dessa forma, analisamos os nomes de três bairros: Cohatrac I, Ipase e Ipem Turu. Esses topônimos são uma mostra de siglas que se ressemantizaram, isto é, adquiriram outros significados. Portanto, descrevemos o léxico toponímico dos três bairros da capital do Maranhão, detalhando de que forma eles documentam o processo habitacional da Cidade. O aporte teórico que sustenta nossa pesquisa está pautado em estudos de Dick (1990) e Curvelo (2009). Os resultados preliminares nos mostram que os topônimos Cohatrac I, Ipase e Ipem Turu documentam não só aspectos antropoculturais, mas físicos.

PALAVRAS-CHAVE: Onomástica. Motivação toponímica. Toponímia ludovicense. Bairros de São Luís.

ABSTRACT: This article investigates the names of the neighborhoods in the Capital of Maranhão, São Luís, specifically, those that arise from institutional acronyms, that is, acronyms of institutes and/or cooperatives that finance housing for a civil society or its associates, agreement, which is a characteristic feature of the housing process in São Luís, thus justifying this research. From hence, analyzing the names of three neighborhoods: Cohatrac I, Ipase and

\footnotetext{
* Graduado em Letras pela Universidade Federal do Maranhão (UFMA) e Mestrando do Programa de PósGraduação em Letras (PGLetras), da Universidade Federal do Maranhão. São Luís - MA. E-mail: Castro.gabriel19@outlook.com.

** Doutora em Linguística pela Universidade Federal do Ceará (UFC), Professora do Departamento de Letras (DELER), da Universidade Federal do Maranhão (UFMA). São Luís - MA. E-mail: helocurvelo@gmail.com.
} 
Ipem Turu. These toponyms are a sample of acronyms that have been re-semantized, that is, they have acquired other meanings. Therefore, describing the toponimic lexicon of these three neighborhoods of the Capital of Maranhão, describing how to document the city's housing process. The theoretical support that sustains our research is based on studies of Dick (1990) and Curvelo (2009). The preliminary results show us that the toponyms Cohatrac I, Ipase and Ipem Turu document not only anthropocultural aspects, but also physical ones.

KEYWORDS: Onomastic. Toponymic motivation. Ludovicense toponymy. São Luís neighborhoods.

\section{Introdução}

O complexo processo de categorização e nomeação daquilo que existe no mundo faz parte de uma necessidade intrínseca do homem e é completamente moldado pela forma como este observa o mundo ao seu redor. Atribuir o nome a um determinado lugar segue esse mesmo processo.

Seguindo essa linha de investigação, temos a Onomástica, ciência que estuda os nomes próprios, bem como o seu processo de nomeação e motivação. Inseridas nessa perspectiva chegamos a duas linhas de estudo: a Antroponímia e a Toponímia. Enquanto aquela se preocupa em descrever os nomes próprios de pessoas, sobrenomes e apelidos, esta investiga a motivação para os nomes dos lugares, ruas, bairros, municípios - os topônimos. Dick (1990, p. 22) define a Toponímia como “[...] a crônica de um povo, gravando o presente para o conhecimento das gerações futuras [...]”, tal definição demonstra a importância dos estudos dessa área de conhecimento, tendo em vista que é por meio desses estudos que podemos rememorar o passado e conhecer um pouco mais acerca de nossa história.

O objeto de estudo da Toponímia são os topônimos e é por meio deles que se pode realizar o que Dick (1990, p. 22) define por projeção temporal, que seria essa rememoração do passado, justamente pelo fato de ser os nomes de lugares a materialização do passado, assim temos, por meio deles, informações concernentes à cultura, à história e às particularidades de um determinado lugar em um dado momento da história. 
Quando observamos um nome de bairro, por exemplo, podemos, a partir dele, depreender inúmeras informações acerca de seu processo formativo, da cultura ali intrínseca e mesmo informações sobre os moradores; assim, o topônimo se constitui para além de um ato puramente nominativo, configurando-se como um ato identitário. Sendo assim, "os topônimos confirmam a tese de que a história das palavras caminha muito próxima à história de vida do grupo que dela faz uso, razão pela qual a ação de atribuir um nome a um lugar corporifica uma soma de diversificados fatores [...]" (ISQUERDO, 2008, p. 36).

Os fatores envolvidos no processo de nomeação do topônimo são os mais diversos, podendo ser puramente linguísticos ou os que envolvem fatores sociais ou extralinguísticos, como: étnicos, socioculturais, históricos, dentre outros. Dessa forma, a Toponímia investiga para além dos aspectos linguísticos que formam o léxico toponomástico, mas, ainda, os fatores que se somam aos linguísticos, influenciando diretamente no ato de nomeação de um topônimo. Isquerdo (2008, p. 36-37) esclarece que:

[...] pelo viés linguístico focalizam-se aspectos como a etimologia, a base linguística dos elementos formativos do nome, a estrutura formal do sintagma toponímico, a classificação taxionômica. Em contrapartida, pelo viés extralinguístico, o topônimo é analisado na perspectiva das causas denominativas que impulsionaram o denominador no ato da nomeação influências étnicas, culturais, históricas, mitológicas e ambientais (ambiente físico e social). (ISQUERDO, 2008, p. 36-37).

Conforme exposto por Isquerdo (2008), percebemos as diversas influências que pairam sobre os topônimos, sendo necessário que os estudemos numa perspectiva plural, considerando tanto os aspectos linguísticos quanto os extralinguísticos para que obtenhamos resultados mais próximos aos que foram pensados no ato de nomeação, na motivação toponímica propriamente dita. Se não estamos presentes no ato da nomeação toponímica, temos que investigar quais fatores foram determinantes para que, em determinado lugar, fosse adotada uma denominação e esta permanecesse ou sofresse Alteração Toponímica (AT). 


\section{Uma característica toponímica ludovicense ${ }^{1}$}

A capital do Maranhão possui um traço bastante específico em seu processo habitacional que é a presença de cooperativas e/ou institutos públicos e privados que construíram e financiaram moradias ${ }^{2}$ para os seus funcionários ou cooperadores. A marca desse processo habitacional característico também de São Luís permanece nos nomes de muitos dos nossos bairros, possibilitando a rememoração desse passado.

Três dessas cooperativas e/ou institutos que fizeram parte do processo habitacional ludovicense e que são fruto de nossos estudos, são: a Cooperativa Habitacional dos Trabalhadores do Comércio - COHATRAC; o Instituto de Previdência e Assistência dos Servidores dos Estados - IPASE e o Instituto da Previdência do Estado do Maranhão - IPEM que, concomitantemente, foram referência para a criação de vários topônimos, dentre eles, destacamos o Cohatrac I, Ipase e Ipem Turu. Assim, buscaremos investigar as causas nominativas desses três topônimos a fim de identificar os fatores linguísticos e extralinguísticos envolvidos no processo de nomeação desses bairros representativos da Capital do Maranhão.

\section{O percurso metodológico e a delimitação do locus}

Como etapas metodológicas para a realização de nossa pesquisa, não pudemos fazer a pesquisa documental porque pouco ou nada há sobre os bairros selecionados neste estudo. Dessa forma, fizemos, prioritariamente, a pesquisa de campo por meio de entrevistas in loco a moradores perfilados dos bairros selecionados. Esses inquéritos foram feitos por meio de instrumentos como: a ficha do informante, o questionário lexicográfico-toponímico e gravador de voz ou celular para que pudéssemos registrar todos os dados coletados para análise. Com o agrupamento das 11 perguntas que compõem o questionário lexicográfico-toponímico, obtivemos informação de natureza

\footnotetext{
${ }^{1}$ Aquele que nasce em São Luís pode ser chamado de ludovicense ou são-luisense. Os maranhenses usam mais o primeiro gentílico: ludovicense.

${ }^{2}$ As cooperativas e institutos habitacionais, nacionais ou não, construíram/constroem tanto casas quanto apartamentos, em condomínios abertos ou fechados para os mais diversos perfis de compradores/financiadores, isto é, moradias de alto padrão e aquelas com preços mais acessíveis, destinadas a trabalhadores que viveriam em áreas populares, como as "cidades operárias".
} 
linguística e social, considerando que as informações extralinguísticas influenciaram diretamente no processo de nomeação dos topônimos.

Os dados prestados pelos informantes foram registrados em gravador e/ou celular, sempre com a devida autorização prévia por parte do morador; as informações pessoais foram preenchidas no ato da entrevista, na parte superior da ficha do informante onde constam as seguintes informações: (i) nome completo; (ii) idade; (iii) endereço; (iv) tempo de moradia e (v) ocupação.

Como não dispomos de dados bibliográficos sobre os topônimos investigados, elencamos um perfil de informante que acreditamos ser o ideal na nossa coleta de dados. Ninguém melhor que um morador genuíno ou de muito tempo de moradia em uma localidade para nos informar sobre as características, sobre as peculiaridades locais. Assim, geramos informações documentais a partir de entrevistas gravadas com o seguinte perfil de informante: (i) morador há pelo menos 20 anos na localidade investigada e/ou que tenha estado presente no início do processo de formação do bairro; (ii) ser, preferencialmente, participante de alguma manifestação artística ou cultural no bairro; (iii) ser, preferencialmente, atuante em alguma associação ou união de moradores do bairro.

Os pré-requisitos para considerarmos um sujeito como nosso informante foram seguidos para que todas as informações prestadas fossem condizentes com a realidade social do espaço geográfico e cultural em que se inserem. E faz-se importante esse tipo de abordagem, com moradores oriundos da localidade, para que, além da motivação toponímica, sejam elucidados fatores relativos ao próprio movimento habitacional que possam ter influenciado no processo de nomeação. É importante dizer que o lugar de fala do informante é nosso único meio de saber sobre os fatores linguísticos e extralinguísticos motivadores da nomeação dos topônimos.

Nossa pesquisa possui natureza toponomástica e objetivou investigar o léxico toponímico concernente a três bairros pertencentes à ilha de São Luís (Cohatrac I, Ipase e Ipem Turu), por isso, um dos critérios para a delimitação do corpus foi considerarmos aqueles topônimos que ainda não haviam sido pesquisados por Curvelo-Matos (2014) e Porto (2018).

Convém ainda esclarecer que consideramos como bairros ou microtopônimos todos aqueles topônimos devidamente registrados pelo Mapa temático de arruamento e 
bairros de São Luís, de 2012, disponibilizado pelo Instituto da Cidade, Pesquisa e Planejamento Urbano e Rural - INCID, órgão da prefeitura de São Luís, responsável pelo levantamento, pesquisa e catalogação dos bairros da Capital. Assim, a seleção dos bairros se pautou em documentos e dados oficias do nosso Município.

Quadro 1 - Ficha do informante e Questionário lexicográfico-toponímico

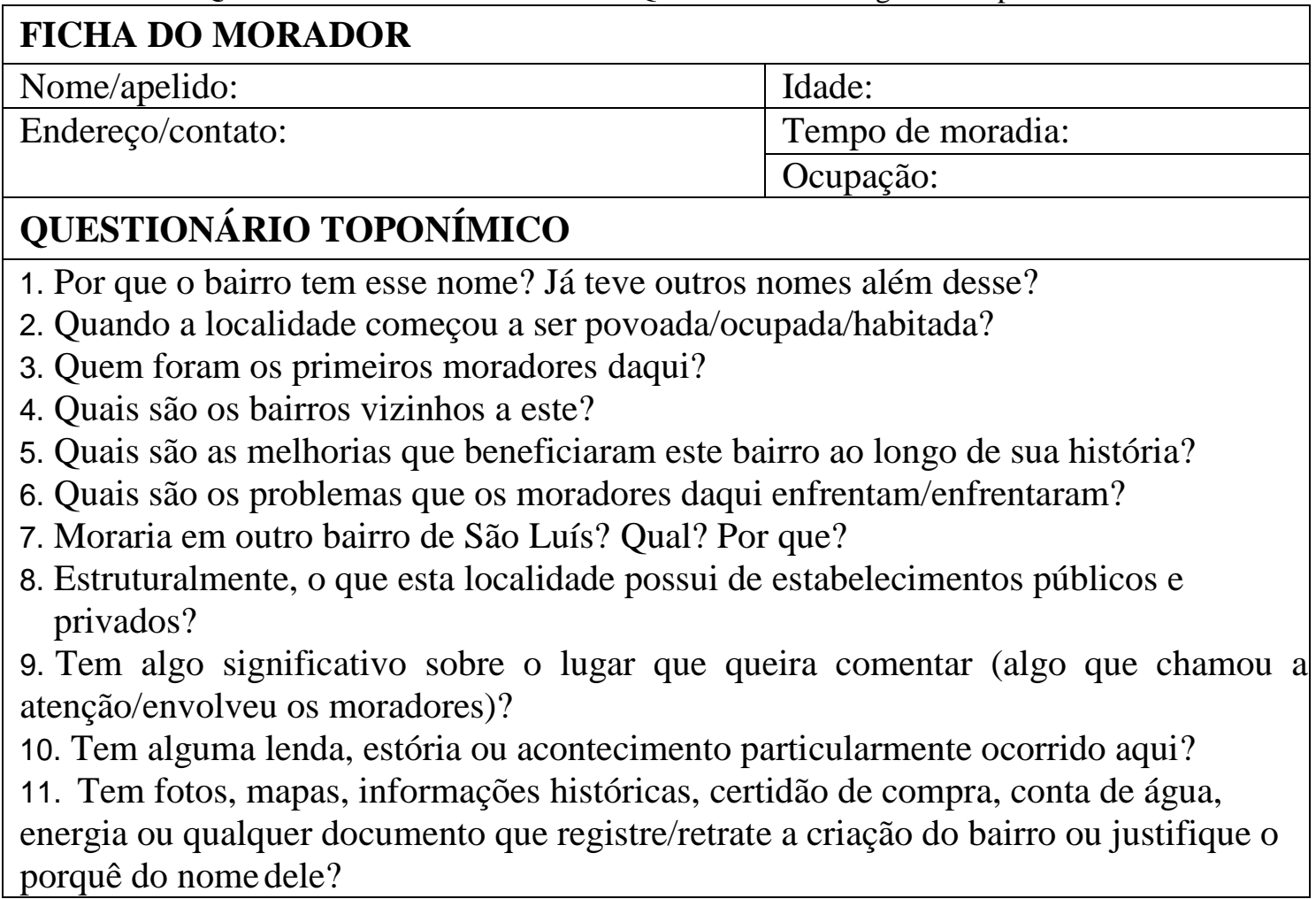

Fonte: adaptado de Curvelo-Matos, 2014.

A ficha toponímica usada para o registro/arquivamento dos dados coletados é composta pelos itens: (i) Topônimo, isto é, o nome do lugar e também os nomes anteriores que o topônimo teve ou suas AT; (ii) Localização do bairro ou local onde o bairro está inserido no espaço geografico da Cidade $^{3}$; (iii) Taxonomia ou a classificação do topônimo de acordo com suas características, tendo como parâmetro o modelo taxonômico proposto por Dick (1990); (iv) Nota linguística que apresenta as informações linguísticas concernentes ao topônimo, (v) Nota histórica com as informações a respeito da história do bairro e de suas respectivas AT (quando há); e (vi) Nota enciclopédica na qual são apresentadas as curiosidades e peculiaridades do topônimo investigado. Apresentaremos, a seguir, um exemplo de ficha toponímica

\footnotetext{
${ }^{3}$ Nessa parte da ficha informamos também os bairros vizinhos ao bairro pesquisado para sermos mais objetivos na localização geográfica do lugar em questão, para tanto, usamos o mapa de bairros e arruamentos de São Luís e também as informações dadas pelos moradores inquiridos.
} 
utilizada em nosso estudo.

\begin{tabular}{|c|c|}
\multicolumn{2}{|c|}{ Quadro 2 - Ficha Toponímica } \\
\hline TOPÔNIMO & \\
\hline LOCALIZAÇÃO & \\
\hline TAXONOMIA & \\
\hline NOTA & \\
LINGUÍSTICA & \\
\hline NOTA HISTÓRICA & \\
\hline NOTA & \\
ENCICLOPÉDICA & \\
\hline
\end{tabular}

Fonte: adaptado de Curvelo-Matos, 2014.

\section{Nomes de bairros de São Luís do Maranhão: o que revelam os topônimos oriundos de algumas siglas institucionais?}

Conforme expusemos ao longo dos nossos procedimentos teóricometodológicos, tentaremos responder ao questionamento proposto em nosso título $(\mathrm{O}$ que nos revelam os topônimos oriundos de algumas siglas institucionais?), considerando todos os dados coletados nos inquéritos feitos aos moradores perfilados dos três bairros em questão neste estudo: Cohatrac I, Ipase e Ipem Turu.

\subsection{Cohatrac I}

O Numerotopônimo ${ }^{4}$ Cohatrac I é formado a partir de uma sigla, que rememora a antiga Cooperativa Habitacional dos Trabalhadores do Comércio - COHATRAC, acrescida de um adjetivo numeral, em algarismo romano (I, para indicar a sequência dos vários bairros surgidos a partir da sigla inicial, a saber: Cohatrac II, Cohatrac III, Cohatrac IV e Cohatrac V).

É interessante notarmos que, mesmo que tenhamos outros Cohatracs, o único oriundo da Cooperativa dos Trabalhadores do Comércio foi o Cohatrac I, os demais surgiram posteriormente sem nenhum vínculo com o primeiro, sendo o Cohatrac I referência toponímica na localidade, característica muito presente na toponímia

\footnotetext{
${ }^{4}$ Segundo Dick (1990), são topônimos constituídos por adjetivos numerais, neste caso, o primeiro de uma série de cinco.
} 
ludovicense.

O bairro Cohatrac I foi construído de forma planejada para servir de moradia aos funcionários da COHATRAC, assim, os primeiros financiavam suas casas de alvenaria conforme suas condições financeiras. Uma das moradoras mais antigas do bairro Cohatrac I, Santos (2019, 14/03/19), nos explica um pouco sobre esse processo:

\footnotetext{
o bairro tem esse nome porque foi uma... associação que foi feita pelos funcionários do comércio... Não é nem associação, é cooperativa, uma cooperativa dos funcionários do comércio, aí eles fizeram essa poupança, né? Pagaram, todos os funcionários do comércio que aderiram a ela, aí fizeram aquela cota e pagaram [...] a cooperativa construiu as casas, né? Aí aquelas pessoas que compraram a cota e foram pagando, pagando todinha, aí eles ficaram com as casas $[\ldots]$.
}

O planejamento feito para a posterior construção do bairro incluía tanto os padrões das casas, todas iguais, como as ruas que são numeradas com letras do alfabeto sequenciadas. Com o passar dos tempos, principalmente com a venda de casas por parte dos primeiros moradores, as casas e ruas foram sendo modificadas e já não têm todas o mesmo padrão; no entanto, ainda é possível observar as marcas do planejamento feito pela construtora dos bairros nas ruas e em algumas casas onde ainda mantêm a estrutura visual planejada.

\subsection{Ipase}

Segundo Curvelo (2009), em seus estudos e proposição, o topônimo Ipase pode ser classificado como um Siglatopônimo, ou seja, um nome de bairro derivado de uma sigla, nesse caso: Instituto de Previdência e Assistência dos Servidores dos Estados IPASE.

A motivação toponímica do Ipase fundamenta-se na adoção da sigla que remete a um órgão público que possibilitou a servidores do Estado a aquisição da casa própria a partir de financiamentos iniciados na década de 1970. Em 1973, as pessoas que adquiriram seus imóveis, começaram a habitá-los, a modificar as casas e, consequentemente, a estruturação das ruas originárias, nomeadas em letras do alfabeto, mas, por motivos de desenvolvimento econômico e de infraestrutura rodoviária, o atual bairro do Ipase foi dividido em dois, ficando bem objetiva sua localização/visualização 
geográfica: Ipase de cima e Ipase de baixo. Sodré (2019, 16/04/2019), morador local, explica que:

(...) antigamente era tudo só Ipase, num tinha nada a ver, aí começou com Ipase alto, por quê? Por causa dessa barreira que tem em frente, né? Aí a parte que ficava mais alto, né? aí foi surgindo as invasões ao redor do conjunto, nele todinho entendeu? Aí o pessoal "tu mora onde?”; "na parte alta, na parte baixa" aí, de boca, aí tipo assim... foi surgindo, parte alta, parte baixa (...) então... por conta disso ficou essa história de Ipase de cima e Ipase de baixo. (...) foi surgindo de boca, assim... num foi dizer que foi... por que era só uma coisa Ipase.

Além de os moradores se referirem às suas moradias situando-as na parte de cima ou na parte de baixo do bairro, os carteiros também utilizavam essa estratégia de localização que se tornou mais evidente visualmente com a ampliação da avenida que corta, literalmente, o Ipase em dois: a Avenida Daniel de la Touche.

Sodré $(2019,16 / 04 / 2019)$ nos informa, ainda, sobre o que, segundo ele, é um dos maiores problemas do bairro:

Por conta também da quantidade de invasões, surge muito a questão social, né? A parte dos ladrões, né? hoje aqui em São Luis, assim, o que eu vejo assim, é que bairro que dá fundo pra mangue a tendência é ter esse pessoal, esses marginais (...) mas num deixa de ter moradores, os primeiro que chegou pra invasão, tem pessoas de bem, a gente num pode dizer que só tem coisa ruim. (SODRÉ, 2019, 16/04/2019).

Para nosso informante (SODRÉ, 2019, 16/04/2019), um problema sério enfrentado pelos moradores do Ipase é a criminalidade, presente em todos os bairros da Capital, independentemente de serem de ocupação espontânea ou não. Mas, a pesar desse desafio, há que considerar que a construção tanto da Avenida Daniel de la Touche quanto da Ponte Governador Newton Bello se constituiu em uma significativa melhoria para os moradores do Ipase e para os ludovicenses porque melhorou o trânsito, possibilitou a valorização imobiliária como também acesso a segurança pública. 


\subsection{Ipem Turu}

O Dirrematopônimo Ipem Turu é formado por duas lexias: a sigla IPEM Instituto da Previdência do Estado do Maranhão, que homenageia e resgata o nome do órgão que financiou a construção de casas próprias a seus funcionários, e Turu, palavra indígena que resgata e memoriza um tipo de lagarta de fogo muito presente na região quando esta começou a ser desmatada para a construção civil. Como a região já era conhecida como Turu na época da entrega do conjunto, o denominador apenas fez uma junção da sigla do Instituto à referência toponímica local, dessa forma, temos o Dirrematopônimo Ipem Turu, isto é, um topônimo composto a partir de uma expressão linguística: ipem+turu. É importante lembrarmos que, em nada a lexia ipem lembra seu processo de formação de palavras inicial (sigla), uma vez que se ressemantizou, tornando-se substantivo próprio.

Não podemos deixar de frisar que, se fossemos classificar as duas lexias separadamente, ipem e turu, elas seriam classificadas, respectivamente, como Siglatopônimo e Zootopônimo, porém, a junção dos dois termos dá origem a um Dirrematopônimo, uma frase ou expressão linguística. Dessa forma, a motivação toponímica para o bairro em questão só apresenta sentido toponímico se considerarmos os dois termos como uma expressão, não sendo possível separá-los sem que haja perda no sentido original, apresentado anteriormente.

O conjunto habitacional Ipem Turu ficou pronto em 1982, contendo um total de 205 casas e 8 ruas nomeadas com números de 1 a 8 . O processo de nomeação também obedeceu a uma sistemática e, sobre ele, uma das moradoras mais antigas, dona Rute de Melo, nos informa que: "[Quando foram] lotear e pra construir, tinha muito turu (...) é um bichinho desse tamanhinho, cheio de cabelinho, entendeu? era uns bichinhos tipo umas lagartinha... e tinha muito turu nos paus, nas árvores. (...) Ipem, foi quem construiu [...]" (DE MELO, 2019, 13/06/19). Esse entendimento é reiterado por dona Sandra Costa $(2019,13 / 06 / 19)$ que, além de nos informar sobre o processo de nomeação, afirma que o Ipem Turu, a princípio, foi construído dentro de outro bairro, o Turu. A informante comenta, ainda, sobre o outro conjunto de casas construído pelo mesmo órgão, nomeado Ipem São Cristóvão: 
O instituto de previdência, nessa época ele construiu o Ipem São Cristóvão e o Ipem Turu pra financiar casa para os trabalhadores (...) Turu é por causa desses bichinho, é tipo uma lagartixa, então o bairro turu é por causa desses bichinhos, o bairro Ipem Turu é porque o instituto construiu dentro do Turu (COSTA, 2019, 13/06/19).

Os funcionários públicos, que desejassem adquirir uma das casas, poderiam escolher entre três tipos de imóveis do padrão, que variavam de acordo com a renda do comprador, assim, existiam as casas: tipo $\mathrm{A}, \mathrm{B}$ e tipo $\mathrm{C}$, que eram destinadas, respectivamente, em ordem decrescente de renda.

Os moradores parecem muito satisfeitos com o lugar onde vivem, pois ali há uma relação bastante afetiva com o bairro, que é diretamente relacionada com a tranquilidade que compartilham. Além de o bairro possuir boa infraestrutura, os moradores possuem uma amizade entre si revelada nos relatos da moradora Costa $(2019,13 / 06 / 19)$ :

Aqui é o seguinte, a vizinhança é muito boa, assim, os vizinhos são muito solidários, não tem violência (...) nós temos uma área bem aí pra fazer caminhada, área de lazer, se eu tiver entediada dia de domingo aqui eu fico conversando com a vizinha, então, aqui tudo é muito bom, e você conhece todo mundo. (...) Todo mundo conhece todo mundo, se alguém adoecer aqui... alguém adoecer todo mundo se conhece, vai pra casa, vai rezar, se tiver passando dificuldade, faz uma vaquinha todo mundo ajuda (...)

Esse tipo de relação entre os moradores acaba sendo rara nos bairros de forma geral; Ipem Turu nos chamou atenção nesse sentido, tanto da satisfação pessoal dos moradores com o bairro, quanto da relação afetiva ainda mantida entre os moradores.

No que tange ao aspecto lexicográfico dos estudos dos topônimos, propriamente dito, na motivação toponímica de Cohatrac I, Ipase e Ipem Turu, encontramos aspectos de natureza física e também antropocultural. Os topônimos estudados nos remetem às siglas dos órgãos que possibilitavam o acesso à casa própria, como é o caso do Instituto de Previdência e Assistência dos Servidores dos Estados - IPASE (Ipase) e da Cooperativa Habitacional dos Trabalhadores do Comércio - COHATRAC (Cohatrac I). O Ipem Turu também faz referência a um desses órgãos, o Instituto da Previdência do Estado do Maranhão - IPEM, porém, traz em seu nome uma referência a uma entidade 
da fauna maranhense; dessa forma, apresenta, como os outros, características de natureza antropocultural mas, ainda, características físico-naturais no mesmo topônimo, o turu (lagarta de fogo, taturana).

\section{Considerações finais}

Ao longo de nossa pesquisa de campo e da análise dos dados obtidos nas aplicações de questionários sobre os bairros Cohatrac I, Ipase e Ipem Turu, pudemos perceber que são muitos os aspectos que podem influenciar na motivação toponímica, neste caso, na ludovicense: processos habitacionais, espelhados por empresas que constroem ou financiam moradias a trabalhadores; desenvolvimento econômico e estrutural da malha viária da cidade; caracterização geográfica onde o bairro se encontra localizado, entre outros aspectos físicos e sociais.

No que tange aos processos de formação linguística dos topônimos, destacamos ainda que Cohatrac, Ipase e Ipem eram originalmente siglas que se referiam a órgãos públicos ou da iniciativa privada que se ressemantizaram adquirindo significação toponímica, uma vez que são usados como substantivo próprio, entrando, portanto, na composição da nomeação dos bairros de São Luís. A seguir, apresentamos um quadro que resume nosso estudo, considerando a classificação taxonômica e aspectos concernentes à motivação toponímica.

Quadro 3-Quadro síntese da pesquisa

\begin{tabular}{|c|c|l|c|}
\hline TOPÔNIMO & CLASSIFICAÇÃO & \multicolumn{1}{|c|}{ MOTIVAÇÃO } & AT \\
\hline Cohatrac I & Numerotopônimo & $\begin{array}{l}\text { Sigla que rememoriza a } \\
\text { Cooperativa Habitacional } \\
\text { dos Trabalhadores do } \\
\text { Comércio-COHATRAC. }\end{array}$ & \\
\hline Ipase & Siglatopônimo & $\begin{array}{l}\text { Sigla que rememoriza o } \\
\text { Instituto de Previdência e } \\
\text { Assistência dos Servidores } \\
\text { dos Estados - IPASE. }\end{array}$ & $\begin{array}{c}\text { Ipase de cima, } \\
\text { Ipase de baixo }\end{array}$ \\
\hline Ipem Turu & Dirrematopônimo & $\begin{array}{l}\text { Sigla que rememoriza: o } \\
\text { Instituto da Previdência do } \\
\text { Estado do Maranhão - } \\
\text { IPEM e um inseto da fauna } \\
\text { local representado pela } \\
\text { lagarta taturana turu. }\end{array}$ & \\
\hline
\end{tabular}

Fonte: os autores. 
É pertinente notar que, conforme exposto no quadro anterior, mesmo que tenhamos três bairros oriundos de um mesmo fenômeno habitacional e sendo todos resultados de siglas que rememoraram os respectivos nomes dos órgãos que financiaram a construção, esses possuem classificações taxonômicas distintas; isso acontece pois a classificação taxonômica deve levar em conta todos os constitutivos do topônimo (linguístico e extralinguístico) a fim de observar de que forma cada item determina o topônimo, como afirma Carvalhinhos (2003, p. 172-173)

[...] vêm justamente resgatando a história social contida nos nomes de uma determinada região, partindo da etimologia para reconstruir os significados e, posteriormente, traçar um panorama motivacional da região em questão, como um resgate ideológico do denominador e preservação do fundo de memória. Nesse sentido, uma área toponímica pode ser comparada a um sítio arqueológico: podemos reconstruir, através do estudo de significados cristalizados de nomes de lugar, fatos sociais desaparecidos, contribuindo com material valioso para outras disciplinas, como a história, a geografia humana e a antropologia.

A partir do exposto por Carvalhinhos (2003, p. 172-173), depreendemos dois pontos centrais dos estudos da Toponímia que explicitam a relevância deste tipo de investigação: (i) o resgate histórico-social que existe no processo de nomeação de um topônimo, que nos permite identificar marcas muitas vezes esquecidas na memória coletiva; (ii) a importância de nossa pesquisa, estando ela entremeada com as áreas correlatas da Toponímia, como a História, a Geográfica, a Sociologia entre outras que nos proporcionam aportes teórico-metodológicos para entendermos os fatores linguísticos e extralinguísticos que influenciaram na nomeação dos lugares.

Convém aclarar, ainda, a forte inserção social presente em nossa pesquisa, uma vez que, diferentemente de outros estudos toponímicos, contamos não apenas com material bibliográfico, mas com entrevistas in loco com informantes representativos de cada um dos bairros pesquisados, obtendo-se, assim, duas diferentes visões sobre um mesmo topônimo. O depoimento dos moradores, voz local, nos permite perceber mais adequadamente as particularidades do contexto do topônimo, pois quem mora na localidade conhece a dinâmica de onde se insere. 
Em síntese, esperamos que o estudo Nomes de bairros de São Luís do Maranhão: o que revelam os topônimos oriundos de algumas siglas institucionais? contribua para que haja uma melhor e mais ampla compreensão dos fatores que foram relevantes no processo de constituição dos três topônimos aqui analisados (Cohatrac I, Ipase e Ipem Turu) já que eles, além de nos revelarem nomes de três instituições públicas que foram decisivas no processo habitacional ludovicense iniciado na década de 1970: COHATRAC, IPASE E IPEM, memorizam um elemento da fauna local que é o nome de uma lagarta taturana (turu) ainda possível de ser vista entre junho e setembro em São Luís em árvores frondosas como pés de manga e bacuri.

A partir de tudo o que foi possível documentar sobre os topônimos ludovicenses Cohatrac I, Ipase e Ipem Turu, podemos afirmar que os nomes de lugares aqui investigados são verdadeiros documentos de fatos, de acontecimentos, muitas vezes esquecidos, perdidos na memória coletiva, na história oficial dos ludovicenses, mas que podem ser resgatados e registrados quando buscamos saber o que nos revelam os nomes dos bairros da Grande Ilha, a Upaon-Açu ${ }^{5}$.

\footnotetext{
${ }^{5}$ Denominação Tupinambá que significa Ilha Grande, um dos topônimos que é conhecida a Ilha de São Luís, capital do Maranhão.
} 


\section{REFERÊNCIAS}

CARVALHO, Maria Aparecida de; DICK, Maria Vicentina de Paula do Amaral. Toponímia da mesorregião centro-sul matogrossense: contribuições para o atlas toponímico do estado de Mato Grosso. 2005. Universidade de São Paulo, São Paulo, 2005.

CARVALHINHOS, Patrícia de Jesus. Onomástica e lexicologia: o léxico toponímico catalisador e fundo de memória. Estudo de caso: os sociotopônimos de Aveiro (Portugal), in: Revista USP, $\mathrm{n}^{\circ}$ 56, dezembro/fevereiro, 2003.

COSTA, Sandra. Inquérito sobre o Bairro Ipem Turu. São Luís, 13/06/2019. (Inquérito realizado por Heloísa Reis Curvelo Matos e Gabriel Pereira Castro).

CURVELO, Heloísa Reis. TOPÔNIMOS MARANHENSES: testemunhos de um passado ainda presente. 282p. 2009. Dissertação (Mestrado em Linguística) - Universidade Federal do Ceará, Fortaleza.

CURVELO-MATOS, Heloisa Reis. Análise toponímica de 81 nomes de bairros de São Luís/MA. 2014. 347f. - Tese (Doutorado) - Universidade Federal do Ceará, Departamento de Letras Vernáculas, Programa de Pós-graduação em Linguística, Fortaleza (CE), 2014.

DE MELO, Rute Maria Matos Cutrim. Inquérito sobre o Bairro Ipem Turu. São Luís, 13/06/2019. (Inquérito realizado por Heloísa Reis Curvelo Matos e Gabriel Pereira Castro).

DICK, Maria Vicentina de Paula do Amaral. A Motivação toponímica e a realidade brasileira. São Paulo: Ed. Arquivo do Estado, 1990.

ISQUERDO, Aparecida Negri. O nome do município. Um estudo etnolinguístico e sóciohistórico na toponímia sul-mato-grossense. Revista Prolíngua. Paraíba, v. 2, n. 2, p. 3452. Disponível em: <http://www.periodicos.ufpb.br/index.php/prolingua>. Acesso em: 13 maio 2019.

PORTO, Laryssa Francisca Morais. Do Centro ao Caminho Grande: estudo da microtoponímia ludovicense a partir dos elementos genéricos presentes nos nomes de 07 bairros surgidos a partir do Antigo Caminho Grande. Relatório (Projeto de Iniciação Científica) - Universidade Federal do Maranhão, 2018, 24p.

PREFEITURA DE SÃO LUÍS. Instituto da Cidade, Pesquisa e Planejamento Urbano e Rural - INCID. Mapa Temático dos Bairros e Arruamento de São Luís, escala numérica aproximada de 1: 40. 000. São Luís: INCID, 2012.

SANTOS, Anair Barros. Inquérito sobre o Bairro Cohatrac I. São Luís, 14/03/2019. (Inquérito realizado por Gabriel Pereira Castro).

SODRÉ, Aliomar Araújo. Inquérito sobre o Bairro do Ipase. São Luís, 16/04/2019. (Inquérito realizado por Gabriel Pereira Castro). 